\title{
A Lei de Responsabilidade Fiscal e a evolução das despesas orçamentárias do estado de Minas Gerais
}

\author{
Gabriella Corrêa Tavares \\ Mestranda em Economia no PPGE-IE/UFRJ \\ E-mail: tavares.gabriellacorrea@hotmail.com \\ Fabricio José Missio \\ Professor da Universidade Federal de Minas Gerais \\ (CEDEPLAR/UFMG) \\ E-mail: fjmissio@cedeplar.ufmg.br \\ Tailiny Ventura \\ Doutoranda em economia no CEDEPLAR/UFMG. \\ E-mail: tailinyventura@hotmail.com
}

Resumo: O objetivo do presente artigo é discutir aspectos da situação fiscal do Estado de Minas Gerais a partir da evolução de três das principais contas de despesas: dívida pública, folha de pagamentos e previdência social. As duas primeiras contas são analisadas sob a ótica do cumprimento dos limites orçamentários instituídos pela Lei de Responsabilidade Fiscal (LRF). Já os gastos com previdência são mensurados a partir do aporte de recursos necessários para cobrir o déficit atuarial do Regime Próprio de Previdência Social. Os resultados mostram uma estrutura orçamentária sustentável até meados de 2015, quando a crise econômica que atingiu o país afetou a execução fiscal do estado. Os anos de 2018 e 2019 apresentaram os piores desempenhos desde 2004, demonstrando a fragilidade fiscal de Minas Gerais no período de recessão econômica e de instabilidade política.

Palavras-chave: Lei de Responsabilidade Fiscal, déficit orçamentário e crise fiscal em Minas Gerais.

Abstract: The purpose of this article is to discuss aspects of the fiscal situation in the State of Minas Gerais based on the evolution of public debt, payroll, and social security. The first two accounts are analyzed from the perspective of compliance with the limits established by the Fiscal Responsibility Law (LRF). On the other hand, social security expenditures are measured based on the contribution of funds necessary to cover the actuarial deficit of the Social Security System. The results show a budget structure that was sustainable until mid-2015 when the economic crisis hit the state's fiscal execution. In 2018 and 2019 the performance was worst that in 2004, demonstrating the fiscal fragility of Minas Gerais in the period of economic recession and political instability.

Key words: Fiscal Responsibility Law, deficit, and fiscal crisis in state of Minas Gerais. JEL Code: E62, E65 
p. 3 - A Lei de Responsabilidade Fiscal e a evolução das despesas orçamentárias

\section{INTRODUÇÃO}

A partir Constituição de 1988 a estrutura do sistema tributário caracteriza-se pela descentralização fiscal, ou seja, estados e municípios ganharam maior autonomia de arrecadação fiscal, acompanhada por maiores transferências de recursos da União. Isso contribuiu para aumentar o poder de decisão desses entes no processo de planejamento e execução orçamentária. O intuito era permitir maior independência nas gestões locais considerando que o país apresenta, historicamente, profundas desigualdades regionais.

Não obstante, ao longo da década de 1990 ficou claro que o novo sistema tributário apresentava problemas. A maior responsabilidade na prestação de serviços por parte dos estados e municípios não teve como contrapartida novos mecanismos que permitissem uma maior arrecadação. Soma-se a isso o fato de que o governo federal adota uma postura defensiva em períodos de crises e escassez de recursos, reduzindo as transferências para as esferas subnacionais.

Ao mesmo tempo observou-se casos de descontrole das contas públicas estaduais e municipais, com o aumento das despesas que não beneficiavam diretamente a população, como aquelas relacionadas a determinados componentes da dívida pública. A resultante foi o cenário bem conhecido de crise nas finanças públicas estaduais.

A partir dessas experiências o governo federal desenvolveu mecanismos no sentido de padronizar o controle fiscal e financeiro dos entes federativos. Nessa perspectiva, foi implementada a Lei de Responsabilidade Fiscal (LRF) no ano de 2000. Essa lei define regras que incide sobre a estrutura orçamentária dos estados. O objetivo é consolidar regimes fiscais sólidos e sustentáveis (SANTOLIN et.al, 2009).

Após a implementação da LRF, a primeira década do século corrente foi marcada por elevadas taxas de crescimento econômico e, simultaneamente, estabilização das contas públicas. Nesse sentido, foi possível expandir os investimentos públicos sem que houvesse a deterioração do resultado orçamentário ${ }^{1}$. E, mais, verificou-se uma melhora substancial no comportamento das contas públicas quando camparados aos períodos anteriores a implementação da LRF.

\footnotetext{
${ }^{1}$ Para uma discussão da relação entre investimento e regime fiscal ver Orair e Siqueira (2016).
} 
Contudo, a partir da recessão econômica de meados da segunda década dos anos 2000, muitos estados entraram em crise fiscal. Em 2016, isso culminou nas situações de calamidade financeira dos estados do Rio de Janeiro, Rio Grande do Sul e Minas Gerais. O problema fiscal desde então não foi solucionado. Em 2019, mais quatro estados juntaram-se a esse grupo: Roraima, Rio Grande do Norte, Mato Grosso e Goiás.A deterioração fiscal dos estados brasileiros traz à tona a discussão sobre a sustenbilidade fiscal dos entes federativos e, do mesmo modo, a efetividade de longo prazo das medidas tomadas nos anos 2000. Nesse contexto, a situação fiscal do estado de Minas Gerais há tempos causa preocupação (OLIVEIRA, 2006). Em janeiro de 1999, o governo mineiro declarou moratória da dívida com a União, visando ajustar as contas estaduais a partir da geração de superávits primários (OLIVEIRA, 2014). Com as limitações estipuladas pela União, o estado sofreu restrições legais que vigoraram até o ano de 2005, período no qual não pôde efetuar novos empréstimos sem antes reequilibrar seu orçamento. Posteriormente, mesmo com uma recuperação geral na sustentabilidade fiscal, que acompanha o desempenho da economia brasileira da época, o estado contraiu diversas outras dívidas entre o período de 2006-2013, principalmente no pós-crise de 2008.

A melhora dos indicadores do estado foi resultante de um aumento na receita e não de uma redução nas despesas. Ou seja, o desempenho fiscal do estado é cíclico, dependente dos períodos de prosperidade econômica. Ademais, isso implica que os sucessivos governos mineiros precisam recorrer ao contingenciamento ou corte dos gastos em períodos de estagnação da atividade econômica. Essa questão faz com que as finanças públicas se tornem um tema central em qualquer debate sobre as perspectivas econômicas de curto e de longo prazo em Minas Gerais

Nesse contexto, este artigo discute o caso mineiro. Essa discussão está centrada na análise da evolução das três principais contas de despesa: dívida pública, folha de pagamentos e previdência social. Em primeiro lugar, verifica-se a evolução da dívida pública e da folha de pagamentos em relação às suas restrições estipuladas pela LRF. Em seguida, analisa-se a evolução do aporte de recursos para o déficit atuarial do Regime Próprio de Previdência Social (RPPS). Por fim, observa-se a evolução dessas variáveis em comparação à receita do governo estadual e ao seu Produto Interno Bruto. O objetivo é, 
p. 5 - A Lei de Responsabilidade Fiscal e a evolução das despesas orçamentárias

ao final, discutir a sustentabilidade fiscal do estado e verificar a efetividade das políticas tomadas em prol do controle orçamentário.

Para tanto, além dessa introdução e das considerações finais, o artigo está organizado em três seções. Na seção 2 apresenta-se um panorama geral da política fiscal no estado de Minas Gerais. Mais especificamente, discute as implicações da LRF. A seção seguinte apresenta uma análise acerca do cumprimento ou não dos limites legais estipulados pela referida lei. Na seção 4 discute-se a questão previdenciária.

\section{LRF E A SITUAÇÃO FISCAL EM MINAS GERAIS}

O Brasil é, historicamente, um país com problemas de endividamento interno e externo ${ }^{2}$. Nesse contexto, a década de 1990 foi marcada por reformas que procuraram evitar a evolução da dívida pública e da inflação. Nos países em desenvolvimento, incluindo o Brasil pós-Plano Real, isso significou seguir um conjunto de medidas inspiradas nas políticas neoliberais (SILVA, 2018), incluindo uma ampla renegociação das dívidas subnacionais e metas para o desempenho fiscal.

No final de 1998, em acordo junto ao Fundo Monetário Internacional (FMI), o Brasil definiu como um dos seus objetivos o alcance da meta de superávit primário. Essa meta seria crescente a fim de evitar a expansão da dívida pública (GIAMBIAGI e ALÉM, 2011; OLIVEIRA, 2014). Ademais, vale ressaltar que nesse período o Brasil adotou um novo modelo de política econômica, o tripé macroeconômico, baseado no regime de metas de inflação, câmbio flexível e superávits primários ${ }^{3}$. A mudança no regime cambial gerou maior instabilidade do valor da dívida pública - indexada ao câmbio - afetando diretamente a sustentabilidade orçamentária de longo prazo do governo (GIAMBIAGI e ALÉM, 2011).

Soma-se a isso o fato que o agravamento da crise financeira dos estados culminou em maior endividamento, resultando em acordos de renegociação com o governo

\footnotetext{
${ }^{2}$ Ver mais sobre a o endividamento histórico da economia brasileira em Abreu (2014) e Giambiagi et al. (2016).

3 Para um melhor entendimento acerca do regime de metas de inflação ver Arestis et. al (2011). Sobre a política fiscal brasileira, sobretudo até o período de 2005, ver Lopreato (2007).
} 
federal ${ }^{4}$. Associado ao descontrole das finanças estaduais, o desempenho fiscal em termos nacionais foi pífio. Assim, no ano 2000, diante da necessidade de regras para alcançar o equilíbrio fiscal e superar a crise de endividamento dos estados brasileiros, o governo federal instituiu a LRF (BRASIL, 2000; GIUBERTI, 2005).

A lei foi instituída com o objetivo de controlar os gastos do governo federal, das unidades federativas e dos municípios e, também, de aumentar a transparência na gestão governamental. Ela está baseada no atrelamento das despesas à capacidade arrecadatória de cada ente federativo. Portanto, em tese, ela rompe com as práticas recorrentes de "pacotes" de recursos para o "socorro" de estados e municípios com problemas de endividamento (SANTOLIN, et.al, 2009) e minimiza os problemas que a descentralização fiscal trouxe para a gestão fiscal a partir da Constituição de 1988.

Mais especificamente, dentre as diversas implicações desta lei tem-se a limitação dos gastos com pessoal e do endividamento das três esferas governamentais, ou seja:

i) Os gastos totais com pessoal não devem ultrapassar $50 \%$ da Receita Corrente Líquida (RCL) para a União e 60\% da RCL para Estados e municípios. Particularmente nos Estados, os gastos devem ser 3\% para o Poder Legislativo, 6\% para o Poder Judiciário, 2\% para o Ministério Público e 49\% para o Poder Executivo;

ii) A Dívida Consolidada Líquida (DCL) não deve ultrapassar 200\% da Receita Corrente Líquida (RCL) nos Estados e no Distrito Federal e $120 \%$ da RCL nos municípios.

Logo, se o estado exceder os gastos no limite prudencial que representa $95 \%$ do limite legal o ente federativo fica, entre outras coisas, proibido de reajustar as remunerações dos servidores públicos (exceto os ajustes determinados legalmente); criar novos cargos, empregos ou função; alterar a estrutura de carreira de forma que aumente as despesas do órgão contratante; contratar pessoal a qualquer título (exceto a reposição de aposentados ou falecidos nas áreas da educação, saúde e segurança); e contratar hora extra (exceto para formação de comissões).

\footnotetext{
${ }^{4}$ Em 1997 foi promulgada a Lei no 9496 de 11 de setembro de 1997, que fez parte do Programa de Apoio à Reestruturação e ao Ajuste Fiscal dos estados.
} 
p. 7 - A Lei de Responsabilidade Fiscal e a evolução das despesas orçamentárias

Adicionalmente, se não houver o cumprimento do limite legal, o estado deve eliminar o percentual do excedente de gastos em até dois quadrimestres por meio da extinção de cargos e funções, redução dos valores atribuídos a cada cargo ou função ou por meio da redução temporária da jornada de trabalho ${ }^{5}$. Após esse período, se o limite não for alcançado, o ente é penalizado e fica proibido de: “I - receber transferências voluntárias; II - obter garantia, direta ou indireta, de outro ente; III - contratar operações de crédito, ressalvadas as destinadas ao refinanciamento da dívida mobiliária e as que visem a redução das despesas com pessoal" (BRASIL, 2000).

Para Minas Gerais, especificamente, os primeiros anos após as disposições da LRF foram marcados pela falta de recursos para realizar investimentos e pela necessidade de enfrentar o desequilíbrio fiscal e melhorar a eficiência da execução orçamentária. Diante desse panorama, em 2003, o programa Choque de Gestão foi formulado e implementado com o objetivo de reduzir significantemente os custos de manutenção do poder público estadual. E, do mesmo modo, efetivar uma configuração institucional mais moderna e dinâmica para o estado mineiro (BENTO, 2015). O programa seguiu um plano estratégico de curto-médio prazo, que buscou o equilíbrio fiscal, e um de longo prazo, com a apresentação de uma agenda de desenvolvimento econômico.

Nessa perspectiva, Silva (2009) relata que o enfoque inicial do programa foi o de avaliar o desempenho das instituições e dos órgãos, com o objetivo de identificar e solucionar problemas, para melhorar a eficiência do aparato estadual. Dentre as medidas realizadas, pode-se destacar: a redução no número de secretarias estaduais (de 21 para 15); a redução dos gastos com pessoal com a extinção de, aproximadamente, $20 \%$ dos cargos públicos; o aumento da arrecadação, com a elevação do Imposto sobre circulação de mercadorias e serviços (ICMS) e do Imposto sobre a propriedade de veículos automotores (IPVA), o qual é recolhido diretamente pelos estados; a redução das horas extras que os servidores públicos podem realizar; a redução de diversos salários da administração pública, como do governador, vice e secretários; entre outras. As medidas do programa Choque de Gestão permitiram que o limite de gastos com pessoal do estado (60\%) não fosse ultrapassado, desconsiderando as despesas de indenização por

\footnotetext{
${ }^{5}$ Nesse caso $1 / 3$ do excedente de gastos deve ser eliminado já no primeiro quadrimestre.
} 
demissão, de incentivos para demissão voluntária e com servidores inativos (BENTO, 2015).

No entanto, mesmo com o referido o programa não houve uma redução do endividamento do estado. Bento (2015) analisa os principais indicadores fiscais do estado de Minas Gerais entre 2004 e 2014 e conclui que a LRF, junto com o Programa Choque de Gestão, teve impacto positivo sobre as finanças públicas mineiras, de forma que os indicadores legais apontam para a sustentabilidade fiscal do estado no período. Contudo, a autora ressalva que "a situação, ainda que positiva, não é confortável, posto o recente déficit primário e fiscal" (BENTO, 2015, p. 96).

Nessa mesma direção, Oliveira (2014) ressalta que, em 2011, o governo troca a dívida com a Companhia Energética de Minas Gerais (CEMIG) (com juros baseado no IGPDI) por outras, quitando a dívida com 35\% de desconto e tomando empréstimos com a Credit Suisse, a Agência Francesa de Desenvolvimento (AFD) e com o Banco Mundial (BIRD). Isso indica que, mesmo com a efetividade do programa sobre o equilíbrio entre receitas e despesas, não houve uma redução do endividamento do estado. Como consequência o estado pode ter dificuldades financeiras em períodos de recessão econômica.

Mais recentemente, com a crise econômica iniciada em 2014, a vulnerabilidade fiscal de Minas Gerais e de muitos outros estados ficou evidente. Mercadante e Oliveira (2017) ressaltam que as políticas observadas até hoje não garantem um bom desempenho fiscal e, nesse sentido, o equilíbrio fiscal permanece dependente da prosperidade econômica e de medidas de austeridade. A queda na atividade econômica comprometeu a arrecadação e o pagamento do serviço da dívida com a União. Isso, junto ao crescimento das despesas obrigatórias, gerou uma deterioração do resultado nominal do estado em questão, elevando a dívida pública.

Em 2016, o governo que assumiu posteriormente ao processo de impeachment promoveu mudanças no regime fiscal brasileiro, assumindo políticas de austeridade fiscal. Assim, em dezembro de 2016, institui-se o Novo Regime Fiscal por meio da Emenda Constitucional no 95/2016 (BRASIL, 2016a), o qual estabeleceu um limite máximo para os gastos do Poder Executivo federal. A Emenda do teto de gastos estabelece que, nos 
p. 9 - A Lei de Responsabilidade Fiscal e a evolução das despesas orçamentárias

próximos 10 anos, as despesas do Executivo ficam congeladas nos valores de 2016, permitindo apenas o reajuste em termos da inflação anual. Nos 10 anos conseguintes, o reajuste poderá ser negociado para outros patamares a cada quatro anos (no primeiro ano de toda nova gestão federal).

Além disso, ao longo de 2016, alguns estados, incluindo Minas Gerais, declararam calamidade financeira por causa do contexto de insolvência da dívida pública. Nesse cenário o governo extinguiu diversos órgãos da administração e atrasou salários de servidores, tentando enquadrar as despesas no valor arrecadado (MERCADANTE e OLIVEIRA, 2017). Para amenizar a situação, em dezembro de 2016, o então presidente Michel Temer sancionou a Lei Complementar no 156, que "estabelece um Plano de Auxílio aos Estados e ao Distrito Federal e medidas de estímulo ao reequilíbrio fiscal" (BRASIL, 2016b). Contudo, o presidente vetou o segundo capítulo da lei, redigido com o objetivo de criar um regime de recuperação fiscal dos estados.

Em maio de 2017, a Lei Complementar no 159 instituiu exceções na Lei de Responsabilidade Fiscal, estabelecendo o Regime de Recuperação Fiscal (RRF) dos estados e do Distrito Federal (BRASIL, 2017). A lei autoriza a suspensão de três anos no pagamento das parcelas da dívida dos estados com a União e, em contrapartida, deve-se privatizar empresas estatais de diversos setores, limitar a contratação de novos empréstimos que não sejam para melhorar o equilíbrio financeiro e revogar isenções fiscais concedidas (MERCADANTE e OLIVEIRA, 2017).

\subsection{Situação Fiscal de Minas Gerais}

A LRF estabele limites para as despesas totais com pessoal e para a DCL em relação à $\mathrm{RCL}$ (em $60 \%$ e $200 \%$ da $\mathrm{RCL}$, respectivamente). Ultrapassar esses limites acarreta punições ao governo estadual.

A Figura 1 mostra a evolução das Despesas totais com Pessoal (DP) em relação à RCL junto com os limites estabelecidos pela LRF em Minas Gerais. Observa-se que no período entre 2004 e 2010, o valor dessa relação esteve abaixo do limite legal de 60\% das DP/RCL. A partir de 2011, verifica-se um aumento constante dessa relação e o limite prudencial deixa de ser alcançado em 2015. Em 2018, o estado ultrapassa em muito o 
limite legal, com a proporção DP/RCL chegando à 76\%. Há uma melhora da situação em 2019 (queda para 67\% na relação DP/RCL), mas o estado continua sem cumprir o limite legal estabelecido pela LRF.

Figura 1 - Despesas Totais com Pessoal em relação à Receita Corrente Líquida, Minas Gerais, 2004-2019

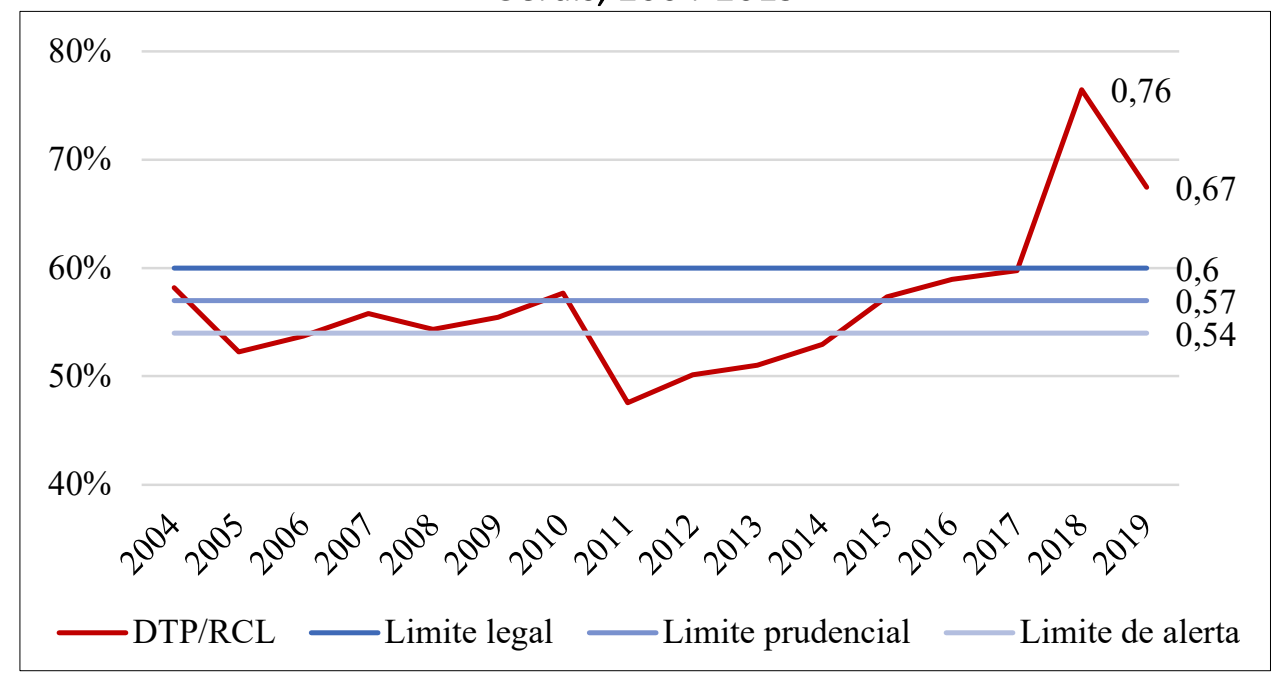

Fonte: Elaboração própria com base nos dados do Relatório de Gestão Fiscal, Consolidado dos Poderes SEF (2020).

Para compreender melhor quando teve início o descumprimento dos limites legais de gastos com pessoal e, do mesmo modo, verificar a possibilidade de punição ao estado, utilizam-se os dados quadrimestrais de 2018 e 2019. Eles são disponibilizados apenas para o Poder Executivo, mas, como este representa aproximadamente $82 \%$ do orçamento mineiro com pessoal, entende-se que é uma boa aproximação. As Despesas Totais com Pessoal do Poder Executivo estiveram acima do limite legal apenas no último quadrimestre de 2018 (Figura 2). Isso decorre, em parte, do pagamento dos salários públicos que estavam atrasados e sendo efetuados parceladamente desde 2016. Como em 2019 essa situação não foi resolvida, o estado tornou-se passível de sofrer as penalizações estabelecidas pela LRF a partir de setembro do referido ano. 
p. 11 - A Lei de Responsabilidade Fiscal e a evolução das despesas orçamentárias

Figura 2 - Despesas Totais com Pessoal Executivo em relação à Receita Corrente Líquida, quadrimestral, Minas Gerais, 2018-2019.

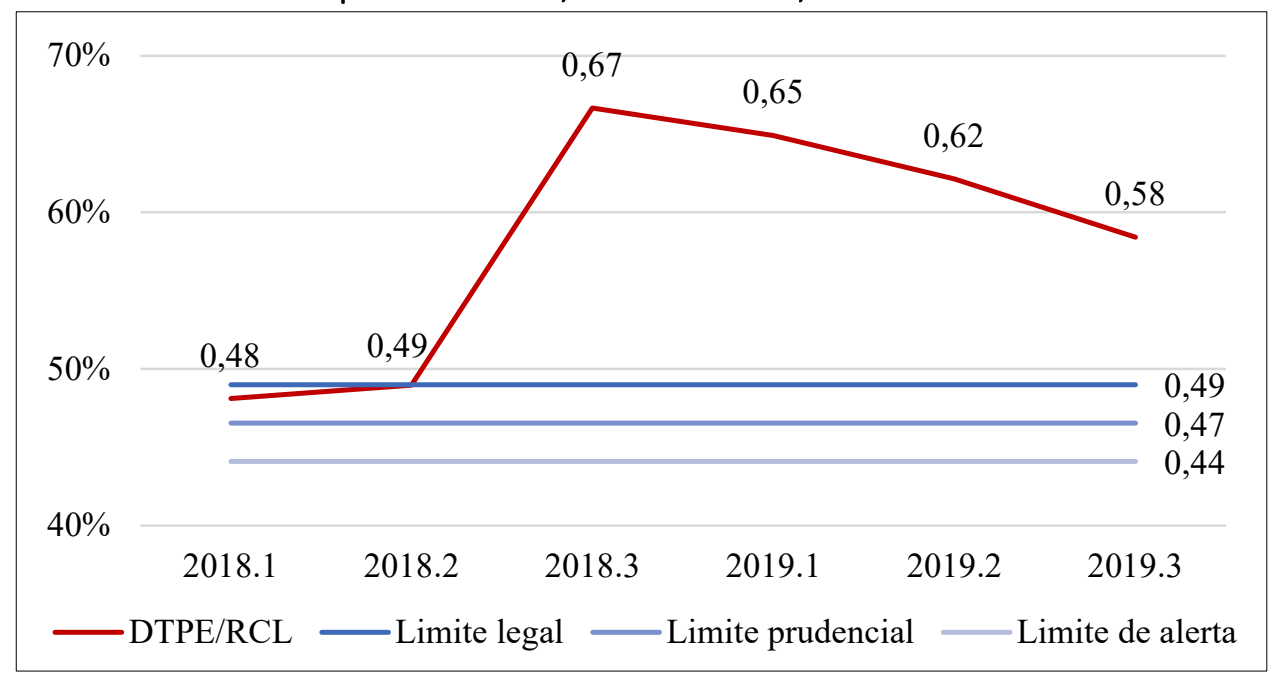

Fonte: Elaboração própria com base nos dados do Relatório de Gestão Fiscal, Consolidado dos Poderes $\operatorname{SEF}(2020)$.

Em relação a dívida do estado de Minas Gerais, os resultados anteriores a 2006 mostram uma situação alarmante. A relação $\mathrm{DCL} / \mathrm{RCL}$ esteve muito acima do limite legal, ultrapassando $220 \%{ }^{6}$. A partir de então, observamos uma certa estabilização da relação DCL/RCL em valores próximos a 180\%. Essa relação cresce em 2015-16, chega a ultrapassar o limite estabelecido pela LRF em 2016, mas ela retorna para níveis inferiores ao limite estabelecido nos anos seguintes.

${ }^{6}$ A variação no nível da RCL entre 2005-2006 gera dúvidas em relação aos resultados divulgados no período. 
Figura 3 - Dívida Consolidada em relação à Receita Corrente Líquida, Minas Gerais, 2004-20197

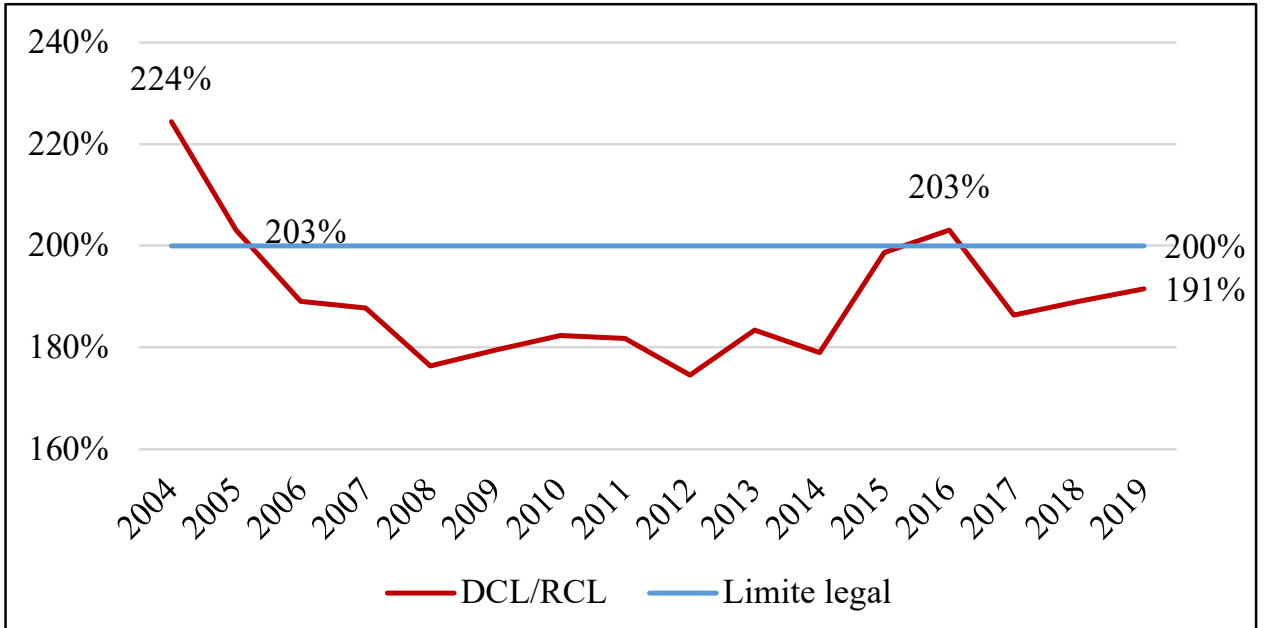

Fonte: Elaboração própria com base nos dados do Relatório de Gestão Fiscal, Consolidado dos Poderes $\operatorname{SEF}(2020)$

A tendência de crescimento acende um sinal de alerta para os próximos anos, tendo em vista as fracas perspectivas econômicas para o biênio 2020-21, acompanhada dos efeitos da crise do Covid-19. Além disso, a LC no 159, de maio de 2017, suspendeu o pagamento das parcelas da dívida com a União até maio de 2020. Assim, a partir de junho de 2020, esses gastos voltam ao orçamento mineiro caso o governo federal não estabeleça alguma medida que solucione essa questão. Esse panorama somado ao desempenho pouco satisfatório da economia mineira pode resultar em maior pressão sobre o resultado fiscal. A partir dessa perspectiva, é importante que o estado prossiga suas atividades com cautela quanto ao orçamento e busque formas alternativas para solução do problema.

A partir do que foi exposto é possível fazer algumas considerações acerca do cumprimento das prerrogativas legais envolvendo o orçamento do estado de Minas Gerais. Em síntese, as despesas com pessoal, crescentes desde 2011, são um alvo da preocupação desde 2015, quando o estado atingiu o limite prudencial da relação DP/RCL e, no ano seguinte, dá início ao processo de parcelamento de salários de funcionários de

\footnotetext{
${ }^{7}$ Considerando-se que a alterações nos valores da $\mathrm{RCL}$ e da $\mathrm{DCL}$ entre os quadrimestres do ano são de pequena magnitude, os dados utilizados para a aproximação de 2019 são referentes ao 2 quadrimestre do ano.
} 
p. 13 - A Lei de Responsabilidade Fiscal e a evolução das despesas orçamentárias

algumas áreas. Sobretudo, elas tornam-se efetivamente um problema constitucional para o governo estadual apenas a partir do 3 quadrimestre de 2018. Já a dívida do estado permanece em patamares elevados ao longo de todo o período analisado, mas sem tendência de crescimento. Mesmo com indícios de mudança nesse quadro nos últimos dois anos, não é possível tirar conclusões definitivas sobre um possível descontrole da dívida mineira.

Ressalta-se que a maior parte da receita corrente do estado é composta pelas receitas tributárias advindas do ICMS (LEAL FILHO e BARBOSA, 2018). Isso permite concluir que, ao menos em parte, o aumento das proporções definidas pela RCL é decorrente da redução das receitas em relação às despesas. Em outras palavras, o desempenho fiscal do estado é amplamente dependente do nível da atividade econômica. Isso implica em restrição financeira e desequilíbrio fiscal em períodos recessivos ou de desaceleração econômica.

\section{A QUESTÃO PREVIDENCIÁRIA EM MINAS GERAIS}

Para verificar a situação previdenciária do estado utilizam-se os dados disponibilizados pela Secretaria da Fazenda em relação às receitas e despesas do RPPS e ao aporte de recursos do estado de Minas Gerais para a previdência social. De forma geral, esses aportes são compostos totalmente de recursos que visam a cobertura de insuficiências financeiras do regime previdenciário. Existem outros pequenos aportes em anos específicos.

A Figura 4 mostra a evolução das receitas e despesas totais do RPPS a partir de 2004. Observa-se o crescimento constante dos gastos previdenciários do estado até 2019. A queda abrupta no nível das receitas entre 2008-09 acontece por uma mudança metodológica: os repasses previdenciários para cobertura de déficit financeiro do RPPS deixam de ser computados dentro das receitas previdenciárias totais e passam a ser considerados separadamente. A metodologia antiga escondia uma discrepância entre as receitas e as despesas do regime de previdência social (figura 4). Observa-se que as receitas não crescem de forma sustentada, enquanto há um crescimento das despesas 
em todo o período em que vigora a nova metodologia. Ou seja, há uma crescente demanda por recursos do governo para manter o regime previdenciário atual.

Figura 4 - Receitas e despesas previdenciárias e aporte de recursos do governo federal, RPPS, R\$ bilhões, Minas Gerais, 2004-2018.

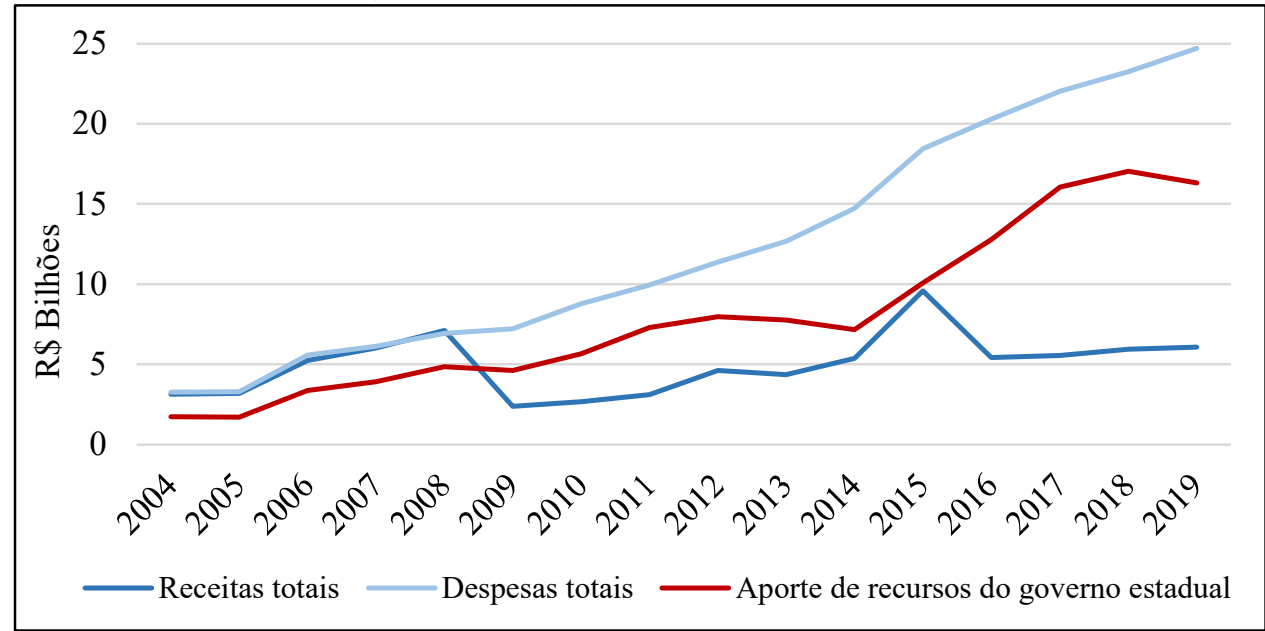

Fonte: Elaboração própria com base nos dados do Relatório Resumido da Execução Orçamentária - SEF (2020).

Esse descompasso nítido entre a entrada e saída de recursos do RPPS sugere uma insustentabilidade da previdência social do estado mineiro. A solução não é de fácil execução, já que essa é uma questão bastante complexa, uma vez que o corte de gastos ou expansão da arrecadação previdenciária é tema sensível. No contexto tanto de acelerado envelhecimento populacional quanto de estruturas fiscais enrijecidas e limitadas, o debate inclui tanto questões sobre o equilíbrio fiscal do estado quanto a necessidade de desafogar as contas públicas e os direitos que o asseguram uma aposentadoria digna aos servidores.

Nesse contexto de desequilíbrio dos regimes previdenciários, a reforma promulgada pelo Senado em novembro de 2019 teve como objetivo equacionar a questão previdenciária, reduzindo o peso da aposentadoria dos servidores aos cofres públicos. As medidas englobam diversos fatores, como o aumento do tempo de contribuição e idade mínima para a aposentadoria, mudança nas alíquotas de arrecadação, entre outros. 
p. 15 - A Lei de Responsabilidade Fiscal e a evolução das despesas orçamentárias

É importante mencionar que o RPPS não abrange os militares ou os deputados estaduais $^{8}$. No caso dos militares, os benefícios previdenciários (como assistência à saúde, auxílio natalidade, auxílio-funeral, entre outros) é de responsabilidade do Instituto de Previdência dos Servidores Militares (IPSM), enquanto as aposentadorias são concedidas pelo tesouro estadual. Já as aposentadorias dos deputados estaduais são responsabilidade do Instituto de Previdência do Legislativo do estado de Minas Gerais (Iple Minas Gerais). O referido instituto passa por um período de extinção. Nesse caso tem-se que:

o deputado passará a se aposentar pelo regime ao qual está vinculado, RGPS [Regime Geral de Previdência Social] ou previdência do servidor público, dependendo de sua origem, podendo complementar o benefício com o novo plano que será criado, desde que contribua para ele (FUNDAÇÃO JOÃO PINHEIRO, 2018).

Assim, considerando que os dados divulgados pela Secretaria da Fazenda não representam a situação total da (in)sustentabilidade da previdência pública, é possível argumentar que a questão do déficit pode estar subestimada. Seria interessante ter maior transparência com relação aos dados, inclusive para que os estudos possam auxiliar nas indicações de alternativas que melhorem a sustentabilidade fiscal do estado.

\section{A SUSTENTABILIDADE FISCAL}

Para entender a sustentabilidade fiscal do estado realiza-se uma comparação entre as relações da DCL, a DP e o Aporte para o $\operatorname{RPPS}^{9}$ (ARPPS) com a RCL e o PIB. Os valores dos três grupos de despesas em relação à RCL se apresentam relativamente estáveis em todo o período (Tabela 1). O ARPPs também apresenta-se estável em relação à RCL entre 2006 e 2014, anos nos quais essa relação alcançou 15,24\% e 15,03\%, respectivamente. Contudo, em 2015 há um salto no nível do gasto com o Aporte para o RPPS, além de uma

\footnotetext{
${ }^{8} \mathrm{O}$ escopo deste trabalho não engloba a previdência dos militares e deputados estaduais pela dificuldade de acesso aos dados, além disso demanda um aprofundamento sobre a estrutura previdenciária do estado. Contudo, ressalta-se a importância de se considerar esses regimes em uma análise investigativa especializada no regime de previdência social. Ademais, é de extrema importância notar que a falta desses dados provavelmente torna o problema previdenciário apontado pelo estudo subestimado.

${ }^{9} \mathrm{O}$ RPPS é operacionalizado pelo Fundo Financeiro de Previdência (Funfip), criado pela Lei Complementar no 64 em 2002, que arrecada e redistribui as contribuições. Caso o montante não seja suficiente, o Tesouro estadual complementa o valor - vide, aporte para déficit do RPPS no RREO.
} 
taxa de crescimento mais acelerado dele em relação à $\mathrm{RCL}$ que permanece até 2018 . Em 2019, mesmo com queda da proporção em relação ao ano anterior, o gasto permaneceu em um nível mais elevado, o que indica uma situação de descontrole do orçamento do RPPS nos anos recentes.

Tabela 1 - DCL, Gasto com Pessoal (GP)e ARPPS em relação à RCL, Minas Gerais, 20062019

\begin{tabular}{|c|c|c|c|c|c|c|c|}
\hline Ano & $\mathrm{RCL}$ & $D C L$ & $\begin{array}{c}\mathrm{DCL} / \mathrm{RCL} \\
(\%)\end{array}$ & GP & $\begin{array}{c}\text { GP/RCL } \\
(\%)\end{array}$ & ARPPS & $\begin{array}{c}A_{R P P S} / \mathrm{RCL} \\
(\%)\end{array}$ \\
\hline 2006 & 22.083.398.894 & 41.755 .007 .307 & $189,08 \%$ & 11.860 .038 .327 & $53,71 \%$ & 3.366 .040 .463 & $15,24 \%$ \\
\hline 2007 & 23.803.678.213 & 44.692.747.095 & $187,76 \%$ & 13.282 .767 .800 & $55,80 \%$ & 3.928 .467 .270 & $16,50 \%$ \\
\hline 2008 & 29.242 .489 .414 & 51.560 .659 .308 & $176,32 \%$ & 15.883 .267 .911 & $54,32 \%$ & 4.857 .873 .667 & $16,61 \%$ \\
\hline 2009 & 29.118.469.548 & 52.264 .414 .523 & $179,49 \%$ & 16.142.113.291 & $55,44 \%$ & 4.631.131.293 & $15,90 \%$ \\
\hline 2010 & 33.179.151.679 & 60.499 .483 .184 & $182,34 \%$ & 19.139.727.560 & $57,69 \%$ & 5.651 .624 .628 & $17,03 \%$ \\
\hline 2011 & 37.284 .183 .548 & 67.779 .833 .155 & $181,79 \%$ & 17.734 .532 .202 & $47,57 \%$ & 7.303.611.300 & $19,59 \%$ \\
\hline 2012 & 40.371.093.301 & 70.461 .770 .698 & $174,54 \%$ & 20.233 .677 .168 & $50,12 \%$ & 7.966.060.121 & $19,73 \%$ \\
\hline 2013 & 43.141 .298 .800 & 79.111.025.393 & $183,38 \%$ & 22.009.791.909 & $51,02 \%$ & 7.754 .743 .642 & $17,98 \%$ \\
\hline 2014 & 47.644 .235 .436 & 85.268 .466 .755 & $178,97 \%$ & 25.221 .858 .676 & $52,94 \%$ & 7.162 .683 .985 & $15,03 \%$ \\
\hline 2015 & 51.643 .235 .767 & 102.592 .255 .535 & $198,66 \%$ & 29.603 .664 .704 & $57,32 \%$ & 10.065 .331 .438 & $19,49 \%$ \\
\hline 2016 & 53.731 .469 .131 & 109.124.343.326 & $203,09 \%$ & 31.662 .953 .045 & $58,93 \%$ & 12.776 .208 .863 & $23,78 \%$ \\
\hline 2017 & 55.173 .574 .560 & 102.814 .921 .151 & $186,35 \%$ & 32.975 .761 .033 & $59,77 \%$ & 16.036 .542 .215 & $29,07 \%$ \\
\hline 2018 & 56.345 .444 .788 & 106.509 .252 .863 & $189,03 \%$ & 43.095 .423 .308 & $76,48 \%$ & 17.051.187.729 & $30,26 \%$ \\
\hline 2019 & 64.068.169.194 & 122.689 .225 .818 & $191,50 \%$ & 43.215 .035 .267 & $67,45 \%$ & 16.051.187.729 & $25,46 \%$ \\
\hline
\end{tabular}

Fonte: Elaboração própria com base nos dados do Relatório de Gestão Fiscal, Consolidado dos Poderes SEF; e do Relatório Resumido da Execução Orçamentária - SEF (2020).

Na Tabela 2, situação similar é apresentada, o que ressalta, novamente, a conexão entre a arrecadação estadual e o desempenho econômico relacionado à produção e comércio. A relação DCL/PIB mostra uma trajetória decrescente até 2012, chegando à aproximadamente 20\% em 2015-16. Essa relação se recuperou no período entre 2017 e 2018, mas ultrapassou 19\% em 2019. Esse resultado mostra que o estado passou por um período favorável à liquidação e redução de sua dívida pública, contudo, isso não perdurou ao longo do tempo. Como resultado, a dívida do estado se mantém elevada.

Os gastos totais com pessoal, por sua vez, permanecem relativamente estáveis em relação ao PIB em todo o período. Com exceção de 2018, período que mostra uma trajetória de crescimento significativa. O mesmo acontece para a relação entre a referida 
p. 17 - A Lei de Responsabilidade Fiscal e a evolução das despesas orçamentárias

despesa e a RCL. Por fim, o ARPPS, que representava menos de $2 \%$ do total do PIB mineiro até 2015 , cresce consideravelmente a partir de então, no mesmo padrão apresentado pela Tabela 1. A relação ARPPS/PIB chega à 2,35\%, 2,80\%, 2,83\% e 2,58\% em 2016, 2017, 2018 e 2019, respectivamente.

Tabela 2 - DCL, GP e ARPPS em relação ao PIB, Minas Gerais, 2006-2018

\begin{tabular}{cccccccc}
\hline Ano & PIB & DCL & $\begin{array}{c}\text { DCL/PIB } \\
(\%)\end{array}$ & GP & $\begin{array}{c}\text { GP/PIB } \\
(\%)\end{array}$ & ARPPs & $\begin{array}{c}\text { ARPPs/PIB } \\
(\%)\end{array}$ \\
\hline 2006 & 212.659 .547 .199 & 41.755 .007 .307 & $19,63 \%$ & 11.860 .038 .327 & $5,58 \%$ & 3.366 .040 .463 & $1,58 \%$ \\
2007 & 240.355 .238 .652 & 44.692 .747 .095 & $18,59 \%$ & 13.282 .767 .800 & $5,53 \%$ & 3.928 .467 .270 & $1,63 \%$ \\
2008 & 278.607 .619 .373 & 51.560 .659 .308 & $18,51 \%$ & 15.883 .267 .911 & $5,70 \%$ & 4.857 .873 .667 & $1,74 \%$ \\
2009 & 287.443 .848 .064 & 52.264 .414 .523 & $18,18 \%$ & 16.142 .113 .291 & $5,62 \%$ & 4.631 .131 .293 & $1,61 \%$ \\
2010 & 351.123 .417 .753 & 60.499 .483 .184 & $17,23 \%$ & 19.139 .727 .560 & $5,45 \%$ & 5.651 .624 .628 & $1,61 \%$ \\
2011 & 400.124 .687 .036 & 67.779 .833 .155 & $16,94 \%$ & 17.734 .532 .202 & $4,43 \%$ & 7.303 .611 .300 & $1,83 \%$ \\
2012 & 442.282 .829 .868 & 70.461 .770 .698 & $15,93 \%$ & 20.233 .677 .168 & $4,57 \%$ & 7.966 .060 .121 & $1,80 \%$ \\
2013 & 488.004 .903 .017 & 79.111 .025 .393 & $16,21 \%$ & 22.009 .791 .909 & $4,51 \%$ & 7.754 .743 .642 & $1,59 \%$ \\
2014 & 516.633 .984 .101 & 85.268 .466 .755 & $16,50 \%$ & 25.221 .858 .676 & $4,88 \%$ & 7.162 .683 .985 & $1,39 \%$ \\
2015 & 519.331 .213 .149 & 102.592 .255 .535 & $19,75 \%$ & 29.603 .664 .704 & $5,70 \%$ & 10.065 .331 .438 & $1,94 \%$ \\
2016 & 544.633 .967 .765 & 109.124 .343 .326 & $20,04 \%$ & 31.662 .953 .045 & $5,81 \%$ & 12.776 .208 .863 & $2,35 \%$ \\
2017 & 571.735 .700 .000 & 102.814 .921 .151 & $17,98 \%$ & 32.975 .761 .033 & $5,77 \%$ & 16.036 .542 .215 & $2,80 \%$ \\
2018 & 601.757 .715 .249 & 106.509 .252 .863 & $17,70 \%$ & 43.095 .423 .308 & $7,16 \%$ & 17.051 .187 .729 & $2,83 \%$ \\
2019 & 632.002 .529 .247 & 122.689 .255 .818 & $19,41 \%$ & 43.215 .035 .267 & $6,84 \%$ & 16.314 .334 .073 & $2,58 \%$ \\
\hline
\end{tabular}

Fontes: FJP; Relatório de Gestão Fiscal, Consolidado dos Poderes - SEF; Relatório Resumido da Execução Orçamentária - SEF (2020).

O volume de aporte de recursos para o RPPS cresce de forma mais acelerada que o PIB, e, do mesmo modo, que a RCL do estado. Isso aponta para a insustentabilidade do regime de previdência ao longo prazo. Além disso, no período recente os gastos com a folha de pagamentos dos servidores apresentam certo descontrole, aumentando de forma mais acelerada nos últimos anos.

Por fim, ressalta-se que a dívida pública não apresenta trajetória explosiva e se mantém em seus limites legais (abaixo de 200\% da RCL), mas seu tamanho em relação ao PIB do estado é substancial, chegando à $20 \%$ em 2016. Isso, junto ao fato de que seu comportamento nos últimos anos é crescente, gera preocupações sobre sua insolvência. Adicionalmente, o baixo crescimento do PIB associado a queda de arrecadação, contribui 
para a tendência de crescimento da relação entre a dívida e o PIB. Tudo isso coloca em risco a sustentabilidade fiscal de longo prazo do estado de Minas Gerais.

\section{CONSIDERAÇÕES FINAIS}

O presente trabalho realizou um estudo acerca da evolução do desempenho fiscal do estado de Minas Gerais pós a implementação da LRF, a partir dos principais componentes da despesa estadual; dívida pública, folha de pagamentos e previdência social. Inicialmente, foi constatado que o estado conseguiu cumprir com os limites legais estabelecidos, para despesas com pessoal e com a dívida consolidada líquida, apresentando, inclusive, redução da dívida do estado durante o período, embora permaneça em padrões considerados elevados. Adicionalmente, a falta de recursos para investimentos fez com que em 2003 o programa Choque de Gestão fosse implementado, contribuindo para o desempenho fiscal. Contudo, a partir de 2011 com efeitos recessivos da crise econômica, os resultados apresentados pelo estado evidenciam algumas fragilidades na execução da política fiscal.

Em síntese, as despesas com pessoal, crescentes desde 2011, são no período atual um elemento da despesa que traz preocupações, sobretudo a partir de 2015. A dívida do estado de Minas Gerais se mantém em níveis elevados, mas não mostra uma trajetória de crescimento. Portanto, não é possível concluir que existe até o momento um descontrole da dívida. De forma geral, a maior instabilidade encontrada nas contas analisadas é nos gastos com o aporte de recursos para o Regime Previdenciário dos servidores públicos do estado. A partir de 2015 a relação entre o Aporte de recursos e a Receita consolidada líquida e o PIB é crescente. Dessa forma, observa-se que não existe uma proporcionalidade entre a arrecadação e concessão dos benefícios.

O que esses resultados em conjunto revelam é que o desempenho fiscal do estado é muito dependente da atividade econômica. Da mesma forma, elucida que a LRF e suas disposições de limites quanto a execução do orçamento aumentou a dependência do desempenho econômico e das transferências do governo federal para a sustentabilidade fiscal. Assim, ressalta-se que embora a política fiscal seja um instrumento contracíclico de estímulo à economia, em períodos recessivos a expansão fiscal do estado é limitada 
p. 19 - A Lei de Responsabilidade Fiscal e a evolução das despesas orçamentárias

pelo receio do acúmulo de dívidas públicas e pela rigidez imposta através das regras orçamentárias. Em outras palavras, a legislação atual impede a ampliação dos investimentos, o que pode prolongar os períodos de recessão econômica.

\section{REFERÊNCIAS BIBLIOGRÁFICAS}

ABREU, Marcelo de Paiva. A ordem do progresso: dois séculos de política econômica no Brasil. São Paulo: Campus, 2014.

ARESTIS, Philip; PAULA, Luiz Fernando de; FERRARI-FILHO, Fernando. A nova política monetária: uma análise do regime de metas de inflação no Brasil. Economia e Sociedade, v. 18, n. 1, p. 1-30, 2009.

BENTO, Carina Di Lorenzo Teixeira. Sustentabilidade fiscal do estado de Minas Gerais: uma análise dos principais indicadores fiscais e da dinâmica da dívida pública. Monografia de conclusão apresentada ao Curso Superior de Administração Pública da Escola de Governo Professor Paulo Neves de Carvalho, da Fundação João Pinheiro, 2015.

BRASIL, Câmara dos Deputados. Emenda Constitucional no 95, de 15 de dezembro de 2016. Altera o Ato das Disposições Constitucionais Transitórias, para instituir o Novo Regime Fiscal, e dá outras providências. Diário Oficial da União, p. 2-2, 2016.

BRASIL, Lei Complementar N. 101. Estabelece normas de finanças públicas voltadas para a responsabilidade na gestão fiscal e dá outras providências. 2000.

BRASIL. Lei Complementar N156, de 28 de dezembro de 2016. Estabelece o Plano de Auxílio aos Estados e ao Distrito Federal e medidas de estímulo ao reequilíbrio fiscal; e altera a Lei Complementar no 148, de 25 de novembro de 2014, a Lei no 9.496, de 11 de setembro de 1997, a Medida Provisória no 2.192-70, de 24 de agosto de 2001, a Lei no 8.727, de 5 de novembro de 1993, e a Lei Complementar no 101, de 4 de maio de 2000. Diário Oficial da União, 2016.

BRASIL. Lei Complementar N 159, de 19 de maio de 2017. Institui o Regime de Recuperação Fiscal dos Estados e do Distrito Federal e altera as Leis Complementares no 101, de 4 de maio de 2000, e no 156, de 28 de dezembro de 2016. Diário Oficial da União, 2016

BRASIL. Lei N 9.496, de 11 de setembro de 1997. Estabelece critérios para a consolidação, a assunção e o refinanciamento, pela União, da dívida pública mobiliária e outras que 
especifica, de responsabilidade dos Estados e do Distrito Federal. Diário Oficial da União, 2016.

FUNDAÇÃO JOÃO PINHEIRO. Diagnóstico da Previdência Pública dos Servidores do Estado de Minas Gerais. Belo Horizonte. (Estatística \& Informações; n. 13). Fundação João Pinheiro, Diretoria de Estatística e Informações, 2018.

GIAMBIAGI, Fabio. As muitas reformas da previdência social. Texto para discussão, 2000. GIAMBIAGI, Fabio. ALÉM, Ana Cláudia. Finanças Públicas-Teoria e Prática no Brasil. Editora: Campus. 1999.

GIAMBIAGI, Fabio; ALEM, Ana; PINTO, Sol Garson Braule. Finanças públicas. Elsevier Brasil, 2017.

GIUBERTI, Ana Carolina et al. Lei de Responsabilidade Fiscal: efeitos sobre o gasto com pessoal dos municípios brasileiros. XXXIII Encontro Nacional de Economia ANPEC, CDROM, Anais da ANPEC, 2005.

LEAL FILHO, Raimundo Souza; BARBOSA, Lúcio Otávio Seixas. O impacto da crise econômica nas finanças públicas estaduais: o caso de Minas Gerais. Brazilian Keynesian Review, v. 4, n. 1, p. 116-132, 2018.

LICIO, Elaine Cristina; MESQUITA, Camile Sahb; CURRALERO, Claudia Regina Baddini. Desafios para a coordenação intergovernamental do Programa Bolsa Família. Revista de Administração de Empresas, v. 51, n. 5, p. 458-470, 2011.

LOPREATO, Francisco LC; PAIVA, C. C. A política fiscal brasileira: limites e entraves ao crescimento. Texto para discussão, n. 131, 2007.

LOPREATO, Francisco Luiz C. Finanças estaduais: alguns avanços, mas...(os exemplos de São Paulo, Rio de Janeiro e Rio Grande do Sul). Econômica, Rio de Janeiro, v. 10, n. 2, p. 187-214, 2008.

MERCADANTE, Paulo Victor; DE OLIVEIRA, Guilherme. A evolução do endividamento público de Santa Catarina pós Lei de Responsabilidade Fiscal. Revista NECAT-Revista do Núcleo de Estudos de Economia Catarinense, v. 6, n. 12, p. 10-35, 2017. 6, no12.

OLIVEIRA, Fabrício Augusto de. O ajuste fiscal de Minas Gerais e o déficit orçamentário zero: a contabilidade que engana. RCA. Revista de Controle e Administração, v. II, p. 171188, 2006. 
p. 21 - A Lei de Responsabilidade Fiscal e a evolução das despesas orçamentárias

OLIVEIRA, Fabrício Augusto de. As finanças do Governo de Minas: esticando a corda do endividamento. XVI Seminário sobre a Economia Mineira. Anais do XVI Seminário sobre a Economia Mineira, 2014.

ORAIR, Rodrigo Octávio; SIQUEIRA, Fernando de Faria. Investimento público no Brasil: trajetória recente e relações com ciclo econômico e regime fiscal. Texto para discussão / Instituto de Pesquisa Econômica Aplicada- Brasília: Rio de Janeiro: Ipea, 2016.

PEREIRA, Hugo Carcanholo Iasco; TANURE, Tarik; TEIXEIRA, André; MISSIO, Fabricio Jose. Uma Perspectiva Crítica do Novo Regime Fiscal para a Dinâmica de Curto e Longo Prazo da Economia brasileira. Revista de Economia do Centro-Oeste, v. 3, p. 51, 2017. SANTOLIN, Roberto; JAYME JR, Frederico Gonzaga; REIS, Júlio César dos. Lei de Responsabilidade Fiscal e implicações na despesa de pessoal e de investimento nos municípios mineiros: um estudo com dados em painel dinâmico. Estudos Econômicos (São Paulo), v. 39, n. 4, p. 895-923, 2009.

SILVA, Karina Fernanda da. As finanças públicas no estado de Minas Gerais: uma avaliação de execução orçamentária no período de 1995 a 2008. Monografia apresentada ao Curso de Especialização em Gestão Pública - VI PROAP da Escola de Governo Professor Paulo Neves de Carvalho da Fundação João Pinheiro, 2009.

SILVA, Rafael Rodrigo dos Santos. A hipótese da contração fiscal expansionista, controvérsias teóricas e evidências empíricas: o caso brasileiro pós-crise 2008. Dissertação apresentada no curso de Mestrado em Economia Aplicada, da Faculdade de Economia, Administração e Contabilidade, da Universidade de Alagoas, 2018. 